Louisiana State University

LSU Digital Commons

$1-1-2011$

\title{
Influence of cortisol on the attachment and metamorphosis of larval Utterbackia imbecillis on bluegill sunfish (Lepomis macrochirus)
}

\author{
Benjamin Dubansky \\ Louisiana State University \\ Brian Whitaker \\ Louisiana State University \\ Fernando Galvez \\ Louisiana State University
}

Follow this and additional works at: https://digitalcommons.Isu.edu/biosci_pubs

\section{Recommended Citation}

Dubansky, B., Whitaker, B., \& Galvez, F. (2011). Influence of cortisol on the attachment and metamorphosis of larval Utterbackia imbecillis on bluegill sunfish (Lepomis macrochirus). Biological Bulletin, 220 (2), 97-106. https://doi.org/10.1086/BBLv220n2p97 


\title{
Influence of Cortisol on the Attachment and Metamorphosis of Larval Utterbackia imbecillis on Bluegill Sunfish (Lepomis macrochirus)
}

\author{
BENJAMIN DUBANSKY*, BRIAN WHITAKER, AND FERNANDO GALVEZ* \\ 208 Life Sciences Building, Department of Biological Sciences, Louisiana State University, \\ Baton Rouge, Louisiana 70803
}

\begin{abstract}
The larvae of unionid freshwater mussels (i.e., glochidia) undergo a parasitic stage requiring their attachment to the external epithelia of fish hosts, where they metamorphose into free-living juveniles. We describe the physiological effects in bluegill sunfish (Lepomis macrochirus) of infection with glochidia from the paper pondshell (Utterbackia imbecillis). Glochidia accumulation on bluegill increased dramatically at concentrations of 2000 glochidia liter $^{-1}$ and above, reaching a maximum attachment density of about 30 glochidia $\mathrm{g}^{-1}$ fish at 4000 glochidia liter $^{-1}$. Plasma cortisol was the most sensitive indicator of biological effect to glochidial exposure, increasing significantly in hosts exposed to 2000 glochidia liter $^{-1}$ or greater. Glochidia were $31 \%$ more likely to undergo successful juvenile metamorphosis when attached to bluegill with elevated plasma cortisol, largely due to the enhanced survivorship of these larvae during the first $48 \mathrm{~h}$ after infection. We tested the hypothesis that glochidial attachment and juvenile metamorphosis were stimulated directly by plasma cortisol in fish hosts. Bluegill were given an intraperitoneal injection of cortisol, then infected with 1000 glochidia liter $^{-1}$ at $48 \mathrm{~h}$ after hormone supplementation. Cortisol-injected fish had a $42 \%$ increase in the number of attached glochidia $\mathrm{g}^{-1}$ fish and a $28 \%$ increase in larval metamorphosis compared to sham-injected and control fish. We provide evidence that cortisol enhances glochidial metamorphosis on hosts by improving the retention of attached glochidia. This study gives insights into the influence of

\footnotetext{
Received 17 September 2010; accepted 7 February 2011.

* To whom correspondence should be addressed. E-mail: bduban1@1su.

Abbreviations: AFW, artificial pond water; Ht, hematocrit.
} edu; orgalvez@1su.edu
\end{abstract}

host physiology on glochidial attachment and juvenile mussel transformation.

\section{Introduction}

Freshwater unionid mussels are the most endangered animals in North America, with more than $70 \%$ of the approximately 300 species in North America threatened or otherwise considered endangered (Williams et al., 1993; Grabarkiewicz and Davis, 2008; Strayer, 2008). The decline in their numbers in recent years is of significant ecological relevance to the southeastern region of the United States, where biodiversity of freshwater mussels is higher than in any other region of the world (Grabarkiewicz and Davis, 2008). Although the possible causes of this loss in biodiversity are varied (Jones et al., 2005), the inability of the larvae to undergo metamorphosis on fish hosts likely contributes to this decline.

Freshwater unionid mussels have a unique life cycle, beginning with their development in the gills of parental mussels. When embryonic development is complete, the larvae, which are also called glochidia, are released from the adults and attach primarily to the gills or fins of fish (Barnhart et al., 2008). Upon attachment, epithelial cells of the host migrate to encapsulate the glochidia, forming cyst-like capsules around the larvae (Dodd et al., 2005; RogersLowery and Dimock, 2006). Depending on the mussel species, a glochidium remains within a cyst for days to months (Arey, 1921, 1932; Waller and Mitchell, 1989; Watters and O'Dee, 1999; Rogers-Lowery and Dimock, 2006), during which time it may metamorphose into a juvenile. Eventually the juvenile mussel will detach from the host fish to continue its life as a free-living benthic organism. Although the transition of a unionid mussel from the larval to the juvenile 
stage requires a host, little is known about the physiological mechanisms regulating this host-ectoparasite interaction.

Each species of glochidia has differing levels of host specificity that dictate the fish species it may utilize as a host (Reuling, 1919; Fustish and Millemann, 1978; Meyers et al., 1980; Rogers and Dimock, 2003; Dodd et al., 2005; Barnhart et al., 2008). Some mussel species are generalists capable of metamorphosing on numerous hosts, whereas others are compatible with a much smaller number of host species (Barnhart et al., 2008). Hosts are also capable of acquiring resistance to glochidia after repeated infections (Dodd et al., 2005; Barnhart et al., 2008), which could also alter the compatibility between glochidia and fish species.

Although the underlying basis for host specificity and host resistance to glochidia are largely unknown, local tissue reactions of the host are likely important in mediating these responses (Arey, 1921; Meyers and Millemann, 1977; Fustish and Millemann, 1978; Meyers et al., 1980; RogersLowery and Dimock, 2006). The localized tissue response in the fish gill to glochidial infection consists of inflammation, hyperplasia, necrosis, and infiltration of different cell populations to the sites of attachment (Arey, 1921; Fustish and Millemann, 1978; Karna and Millemann, 1978; Meyers et al., 1980; Waller and Mitchell, 1989). Although these effects are seen in all glochidia-infected fish to some degree, their magnitude is greatly exaggerated in resistant or nonhost fish (Bauer and Vogel, 1987a, b; Waller and Mitchell, 1989; Dodd et al., 2006). These enhanced localized responses may lead to incomplete cyst formation after attachment of glochidia to the fish gill, and subsequently to the premature shedding of these larvae (Reuling, 1919; Fustish and Millemann, 1978; Dodd et al., 2006; Rogers-Lowery and Dimock, 2006). It is thought that these mechanisms account for the early shedding of glochidia from resistant fish (Waller and Mitchell, 1989; Rogers and Dimock, 2003). Understanding the influence of host physiology on these gill-level effects may help describe the specific requirements for successful metamorphosis of glochidia on host fish.

The fish gill is the primary organ for maintenance of whole-animal homeostasis in the fish (Evans et al., 2005; Perry and Gilmour, 2006). It is also the primary site for the introduction of potentially pathogenic organisms into the body (Campos-Perez et al., 2000; Sollid and Nilsson, 2006). Tissue-level responses to glochidia may potentially impair gas exchange, ion homeostasis, and acid-base balance, all of which are physiological functions primarily regulated at the gills (Evans et al., 2005). At high levels of glochidial infestation, gill burdens may be severe enough to kill the fish host (Meyers and Millemann, 1977; Howerth and Keller, 2006), jeopardizing the continued development of the glochidia. At low to moderate levels of glochidial infection, it is likely that the host will undergo a stress response, which may affect host immunity, and thus influ- ence glochidial survivorship on the host. It follows that changes in the physiological status of potential fish hosts may ultimately affect the efficacy of glochidial attachment and metamorphosis (Bogan, 1993; Gillis et al., 2008; Strayer, 2008).

The objectives of this study were to investigate the effects of glochidial exposure on various physiological endpoints broadly indicative of host stress, including plasma cortisol, lactate, glucose, sodium, and blood hematocrit. We demonstrated that exposure to high concentrations of glochidia resulted in elevated plasma cortisol in hosts, and that at these high glochidial concentrations, more glochidia attached to hosts and a greater percentage of glochidia metamorphosed into juveniles. We also set out to test the hypothesis that exogenous administration of cortisol to fish could directly affect the ability of glochidia to attach and metamorphose following infection. To our knowledge, this is the first study involving controlled experimental infections measuring the teleost stress response and its effects on glochidial metamorphosis in host fish.

\section{Materials and Methods}

\section{Animals}

Bluegill sunfish (Lepomis macrochirus Rafinesque, 1819) were obtained from Pond Pro, LLC (Liberty, MS) where fish were reared in small ponds that had no signs of mussel shells or live animals; we confirmed absence of mussels by inspecting the ponds after draining. All fish were transported to the Department of Biological Sciences Aquatic Facility at Louisiana State University, where the facility was maintained on a 12-h light cycle. Prior to experimental infections with glochidia, fish were acclimated at $21-23{ }^{\circ} \mathrm{C}$ for at least 1 month in 380-liter polyethylene tanks in artificially formulated pond water (AFW) (Dietz et al., 1994) under recirculating conditions. Fish were fed $40 \%$ protein fish pellets (Cargill Aquaxcel) at a ration of 3\% body weight per day. For experimental infections, glochidia of the paper pondshell mussel (Utterbackia imbecillis Say, 1829) were utilized. $U$. imbecillis is a host generalist capable of parasitizing a wide array of fish, including the bluegill (Watters and O'Dee, 1998; Rogers-Lowery and Dimock, 2006). This species can be found gravid year round in small ponds in East Baton Rouge Parish, Louisiana. Gravid mussels were collected as needed and transported to Louisiana State University, where they were utilized upon arrival, or held in 19-liter containers for no longer than 3 weeks under static conditions in native pond water at $21-23{ }^{\circ} \mathrm{C}$. Mussels were fed a mix of live or freeze-dried algae weekly.

Glochidia were isolated from gravid mussels using a protocol slightly modified from that of Dodd et al. (2005). Briefly, the outer demibranchs of each gravid mussel were cut down the midline and flushed into a 1000-ml beaker with a stream of AFW from a plant sprayer. The mixture 
was briefly stirred until aggregates of glochidia and mucus formed. A pipette was used to transfer these mucus-bound glochidia to a $25-\mathrm{ml}$ beaker. A gentle stream of AFW was focused on the mass to dislodge the glochidia, which were allowed to overflow back into the 1000-ml beaker. Glochidia from each mussel were held in separate 1000-ml beakers and washed twice with AFW. The glochidia from each mussel were assessed for viability by removing a $100-\mu \mathrm{l}$ aliquot of glochidial suspension from each mussel, followed by the addition of $\mathrm{KCl}$ crystals. Open glochidia that closed upon addition of $\mathrm{KCl}$ were considered viable. The ratio of viable glochidia to total glochidia was used to determine the percentage of viable glochidia for each mussel. Mussels with $>90 \%$ viable glochidia were pooled and utilized for experimental infections.

All animals were housed and handled according to Institutional Animal Care and Use Committee Protocol \#07-053. Animal care facilities were managed by the Department of Laboratory Animal Medicine, Louisiana State University, School of Veterinary Medicine, and accredited by the Association for Assessment and Accreditation of Laboratory Animal Care International.

\section{Infection procedures}

Initial infections were conducted in 19-liter glass aquaria to determine an optimal fish size for subsequent experiments. Sixty fish, ranging in size from 0.26 to $22.92 \mathrm{~g}$, were exposed in small groups $(n \leq 6)$ to 4000 glochidia liter $^{-1}$ in AFW for 25 min. Glochidia were kept in suspension by moving water with a $25-\mathrm{ml}$ serological pipette. After infections, fish were killed and gill arches isolated into chilled phosphate-buffered saline (PBS) awaiting analysis of gill infection intensity using a stereomicroscope (Zeiss, SteREO Lumar.V12). The number of glochidia attached to each gill arch was counted to estimate total gill burden.

For all other experiments, an automated infection system was developed to minimize human interaction with the fish. Each system consisted of a 19-liter conical-bottomed tank affixed with a drain to collect glochidia. An air-driven plumbing system gently recirculated the glochidia to the top of the tank, then across a baffle to resuspend them evenly throughout the tank. Plumbing was designed to accommodate both recirculating and flow-through capabilities. Prior to infection, fish were allowed to acclimate to the infection systems for $48 \mathrm{~h}$ under flow-through conditions. At the start of infections, each system was switched to recirculating conditions and glochidia added as described below. After infection, the chambers were switched to flow-through conditions by flushing with AFW for at least 10 min to remove glochidia.

\section{Physiological response to infection}

Thirty bluegill $(14.06 \pm 0.30 \mathrm{~g})$ were randomly divided into five groups $(n=6)$ and acclimated to five infection chambers for about $48 \mathrm{~h}$ prior to exposure to glochidia at concentrations of $0,1000,2000,4000$, and 8000 glochidia $\operatorname{liter}^{-1}$ for $25 \mathrm{~min}$. Fish were sampled $24 \mathrm{~h}$ after exposure, and their body mass and fork-length were recorded. Blood was collected from the caudal peduncle in ammonia-heparinized micro-hematocrit $(\mathrm{Ht})$ capillary tubes (Fisher Scientific, 22-362-566), then centrifuged in a micro-capillary centrifuge (International Equipment Company, model MB). The $\mathrm{Ht}$ of each fish was calculated as the percentage of packed red blood cells to total blood volume. Plasma from each fish was collected, flash-frozen in liquid nitrogen, and stored at $-80{ }^{\circ} \mathrm{C}$ until further processing. Plasma sodium ion concentrations were measured by flame atomic absorption spectroscopy (Varian, AA240FS). Plasma cortisol concentrations were measured by radioimmunoassay (Diagnostic Systems Laboratories, DSL-2100). Plasma glucose was measured using a 96-well glucose assay kit (Cayman Chemicals, 10009582), and plasma lactate was measured with a lactate meter (Nova Biomedical, Lactate Plus).

\section{Influence of infection intensity on metamorphic success and attachment}

Twenty-four bluegill $(13.33 \pm 1.52 \mathrm{~g})$ were divided randomly into four groups $(n=6)$. Each group was infected as described above at concentrations of 1000, 2000, 4000, and 8000 glochidia liter ${ }^{-1}$. After infections, fish were immediately transferred into a custom-built system designed for monitoring the shedding of glochidia and juveniles from individual fish. Briefly, self-cleaning 2.8-liter tanks (Aquaneering, San Diego, CA) were arranged on a multi-level shelving unit equipped with a recirculating water delivery system capable of distributing water to the individual tanks. Water delivered to each tank was directed across the bottom of the tanks and through an overflow spout, effectively removing $>95 \%$ of the glochidia in a tank within $45 \mathrm{~min}$ (data not shown). Each tank was outfitted with a $100-\mu \mathrm{m}$ filter to collect debris from the overflow. The contents of each filter were examined daily under a stereomicroscope for the presence of glochidia and juveniles. The number of glochidia attached to the hosts during infection was calculated from the sum of glochidia and juveniles recovered from each fish during the 10-day post-infection period. The total number of mussels recovered from each fish was divided by the mass of each fish to give an estimate of attachment $\mathrm{g}^{-1}$ fish. Metamorphosis success was determined according to the ratio of juveniles to total mussels shed from each fish during the duration of infection. By monitoring the emergence of glochidia and juvenile mussels each day, the time required until the first emergence of juveniles (Rogers and Dimock, 2003) and the total duration during which 
juveniles were shed from host fish (Dodd et al., 2005) were calculated.

\section{Effects of exogenous cortisol on metamorphic success}

Eighteen bluegill sunfish $(27.17 \pm 0.86 \mathrm{~g})$ were divided into three groups $(n=6)$. One group of fish was administered a dosage of $0.2 \mathrm{mg} \mathrm{g}^{-1}$ fish of hydrocortisone 21hemisuccinate (Sigma, H4881), hereafter referred to as cortisol, dissolved in warm coconut oil. Injections were performed intraperitoneally at a volume of $4 \mu \mathrm{g} \mathrm{g}^{-1}$ fish using a 26-gauge needle. A second group of fish was shaminjected with coconut oil at a volume consistent with the cortisol-laden injections. An additional group of non-injected fish was also included, and was otherwise handled identically to the cortisol and sham-injected fish. All fish were allowed to recover from injections and handling for $48 \mathrm{~h}$. All three groups were then infected with 1000 glochidia liter ${ }^{-1}$ and monitored for 14 days post-infection to assess glochidial attachment and metamorphic success for each fish, as described above.

\section{Statistics}

Linear regression was performed using Microsoft Excel. Statistical analysis was performed with XLSTAT ver. 2010.3.03. Variables were compared using the KruskalWallis test, followed by Dunn's pairwise comparison if they did not meet assumptions of parametric normality. Normally distributed data sets were compared using one-way ANOVA followed by Tukey's (honestly significant difference) pairwise comparison with a 95\% confidence interval. All values were presented as means \pm SE. Criteria for significant differences were at $P \leq 0.05$ for all comparisons.

\section{Results}

Initial infections demonstrated a relationship between fish mass and gill glochidial burdens, increasing in an exponential fashion (Fig. $1 \mathrm{~A}, R^{2}=0.61$ ). This relationship was most evident in fish weighing at least $8 \mathrm{~g}$, with glochidial gill burden increasing about 4-fold between $8 \mathrm{~g}$ and $23 \mathrm{~g}$ (Fig. $1 \mathrm{~A}, \mathrm{~B})$. Plotting these data on log-log scales linearized this relationship, providing a power function of $2.19\left(R^{2}=\right.$ 0.61). On the basis of these data, we chose to conduct subsequent experiments with fish weighing no less than $8 \mathrm{~g}$ whenever possible, in order to increase the probability of glochidial accumulation on fish gills during infections.

Fish were infected with glochidia at concentrations ranging from 0 to 8000 glochidia liter $^{-1}$ for $25 \mathrm{~min}$ using automated infection chambers, then assessed for various hematological endpoints at 24-h post-infection. There was a significant increase in plasma cortisol in fish exposed to 2000, 4000, and 8000 glochidia liter $^{-1}$ compared to fish infected with 0 or 1000 glochidia $\operatorname{liter}^{-1}(P<0.03)$ (Fig. 2,
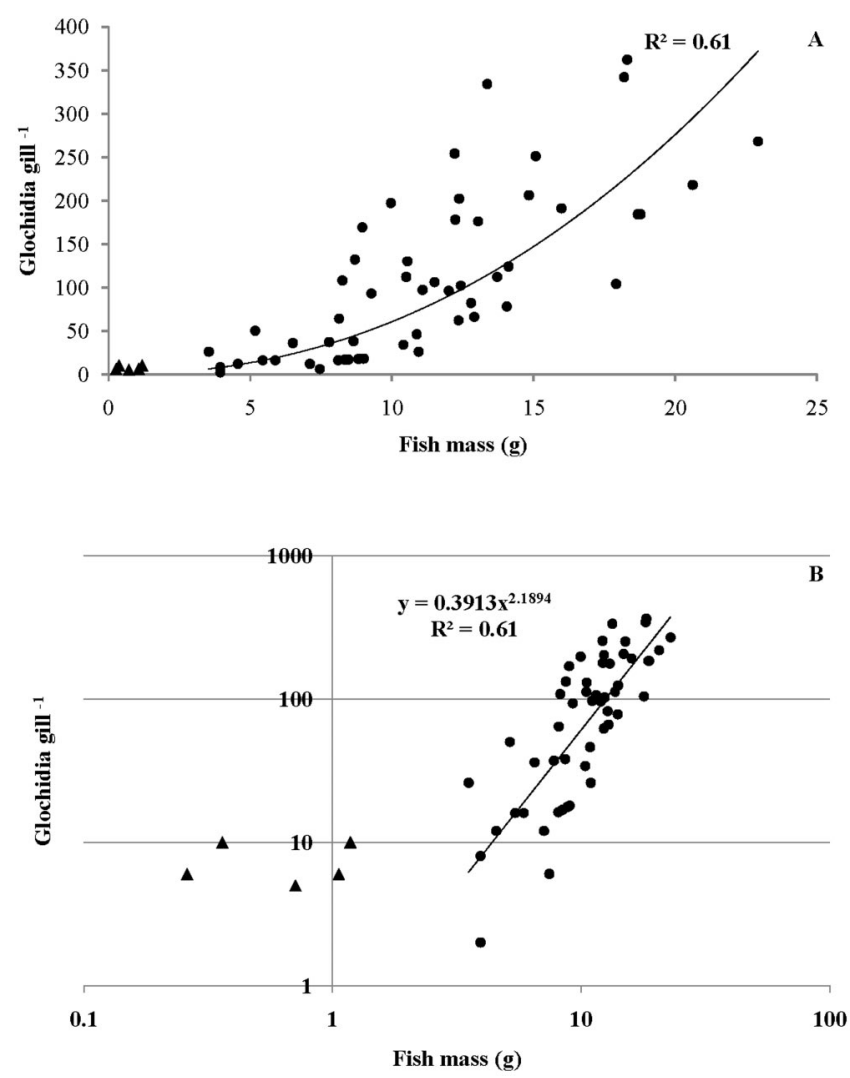

Figure 1. Sixty fish were exposed in small groups to 4000 glochidia liter $^{-1}$ for $25 \mathrm{~min}$. The number of glochidia attached to the fish gills was determined using stereomicroscopy. (A) Nonlinear regression of the number of attached glochidia on the gills of each fish versus fish mass (g). (B) Same data as in A, plotted on log-log scales. Circles represent the data for fish used in establishing the line of best-fit through the data. Triangles represent the data for fish that were excluded in the line of best-fit. $R^{2}$ is the correlation coefficient for the line of best-fit calculated using nonlinear regression.

Table 1). In comparison, there were no significant differences between treatments in plasma glucose, lactate, and sodium (Table 1). There was no clear pattern of effect in blood $\mathrm{Ht}$ with regard to glochidial infection concentration. Ht was significantly elevated in the fish exposed to 0, 2000, and 8000 glochidia liter $^{-1}$ compared to those exposed to 1000 and 4000 glochidia liter $^{-1}$ (Table 1).

A separate group of fish was infected with glochidia at concentrations ranging from 1000 to 8000 glochidia liter ${ }^{-1}$ to assess the pattern of shedding of immature glochidia and mature juveniles from hosts over time (Fig. 3). These data were used to calculate the mean time required for the first appearance of juvenile mussels from hosts (Table 1). Juvenile mussels began to emerge from host fish about 0.6 days sooner when fish were infected with 4000 and 8000 glochidia liter $^{-1}$ compared to 1000 glochidia $\operatorname{liter}^{-1}(P=$ 0.027 ) (Table 1, Fig. 3). Once the first juvenile mussels began to emerge, the average duration of time during which juveniles were shed from hosts was significantly longer by 


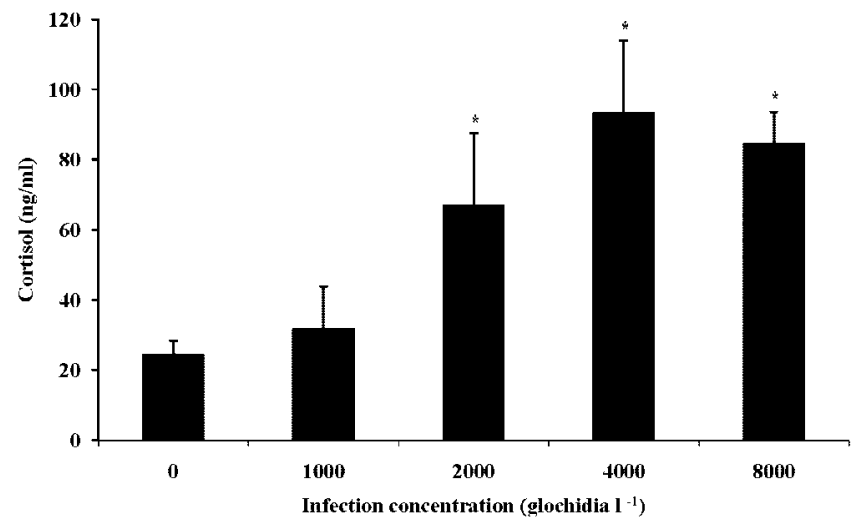

Figure 2. Plasma cortisol concentrations of host fish sampled $24 \mathrm{~h}$ after infection with glochidia ranging in concentrations from 0 to 8000 glochidia liter ${ }^{-1}$ for $25 \mathrm{~min}$. Values represent the mean plasma cortisol \pm SE $(n=6)$. Bars with asterisks are statistically different from the 0 and 1000 liter $^{-1}$ infection concentration $(P<0.03)$.

about 1.5 days for fish infected at 4000 and 8000 glochidia

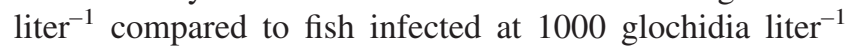
$(P<0.002)$ (Table 1, Fig. 3). These data (Fig. 3) were used to calculate the number of attached glochidia per fish as attachment $\mathrm{g}^{-1}$ fish (Fig. 4A) and to determine metamorphic success (Fig. 4B). Mean number of attached glochidia $\mathrm{g}^{-1}$ fish mass was significantly elevated in hosts infected with 2000, 4000, and 8000 glochidial liter ${ }^{-1}$ compared to those infected at 1000 glochidia liter $^{-1}(P<.001)$ (Fig. 4A). Mean metamorphic success was significantly elevated from $48.8 \%$ $\pm 12 \%$ in fish infected at 1000 glochidia $\operatorname{liter}^{-1}$ to an average of $79.9 \% \pm 1 \%$ in infection concentrations at or above 2000 glochidia liter $^{-1}(P<0.01)$ (Fig. 4B).

Experiments were conducted to assess whether cortisol supplementation of hosts prior to infection could influence the attachment and the subsequent metamorphosis of glochidia after a standard 1000 glochidia liter ${ }^{-1}$ infection, a concentration that was previously found not to increase endogenous plasma cortisol (Fig. 2). The first appearance of juveniles was observed on day $6.0 \pm<0.01$ for all shaminjected and cortisol-injected fish, and the first appearance of juveniles occurred in the control group on day $7.0 \pm<$ 0.01 day post-infection (Fig. 5). The average duration of juvenile shedding for the cortisol-injected fish lasted $5.5 \pm$ 0.43 days (Fig. 5). This value was significantly different than the duration of $3.0 \pm 0.41$ days calculated from the control fish $(P=0.003)$. There was no statistical difference between the cortisol-injected and sham-injected fish $(P=$ 0.16 ). The mean number of attached glochidia $\mathrm{g}^{-1}$ fish was $49.9 \%$ higher in cortisol-injected fish than in control fish $(P$ $=0.01$ ) (Fig. 6A). The number of attached glochidia was $34.9 \%$ higher in cortisol-injected fish than in sham-injected fish $(P=0.12)$. Additionally, mean metamorphic success was significantly elevated to $90 \% \pm 1.12 \%$ in fish that were administered cortisol injections compared to both control and sham-injected fish, which had metamorphic values of $62 \% \pm 6.18 \%$ and $60 \% \pm 6.00 \%$, respectively $(P<0.005)$ (Fig. 6B).

During the first $48 \mathrm{~h}$ after infection, shedding of glochidia was at its peak for all treatment groups. To identify differences in the shedding during this time, the number of mussels shed during the first $48 \mathrm{~h}$ was examined. The percentage of the total that were shed as glochidia in the first $48 \mathrm{~h}$ post-infection was about $47 \%$ $\pm 9 \%$ for fish infected with 1000 glochidia liter ${ }^{-1}$, compared to about $13 \%$ to $18 \%$ for fish infected with between 2000 and 8000 glochidia $\operatorname{liter}^{-1}(P=0.001)$ (Fig. 4C). The percentage of the total number of attached mussels shed as glochidia in the first $48 \mathrm{~h}$ post-infection was approximately $7 \% \pm 1 \%$ for fish injected with cortisol compared to about $30 \%$ for control and sham-injected fish $(P<0.03)$ (Fig. 6C).

Table 1

Effects of glochidial infection on hematological variables and shedding dymamics

\begin{tabular}{|c|c|c|c|c|c|c|c|}
\hline $\begin{array}{c}\text { Infection } \\
\text { (glochidia } \\
\text { liter }^{-1} \text { ) }\end{array}$ & Hematocrit & $\begin{array}{c}\mathrm{Na} \\
\left(\mathrm{mmol} \mathrm{1}^{-1}\right)\end{array}$ & $\begin{array}{l}\text { Glucose } \\
(\mathrm{mg} / \mathrm{dl})\end{array}$ & $\begin{array}{l}\text { Lactate } \\
\left(\mathrm{mol} \mathrm{l}^{-1}\right)\end{array}$ & $\begin{array}{l}\text { Cortisol } \\
(\mathrm{ng} / \mathrm{ml})\end{array}$ & $\begin{array}{l}\text { Time until juvenile } \\
\text { shedding (days) }\end{array}$ & $\begin{array}{l}\text { Duration of juvenile } \\
\text { shedding (days) }\end{array}$ \\
\hline 0 & $0.26 \pm 0.013^{*}$ & $151.0 \pm 5.58$ & $53.7 \pm 5.27$ & $1.38 \pm 0.17$ & $24.5 \pm 3.85$ & N/A & N/A \\
\hline 1000 & $0.25 \pm 0.007$ & $150.2 \pm 4.17$ & $54.4 \pm 7.32$ & $1.24 \pm 0.27$ & $31.7 \pm 12.13$ & $6.0 \pm<0.01$ & $2.2 \pm 0.02$ \\
\hline 2000 & $0.27 \pm 0.002^{*}$ & $142.8 \pm 4.33$ & $52.4 \pm 6.17$ & $1.52 \pm 0.23$ & $66.7 \pm 20.85^{*}$ & $5.8 \pm 0.17$ & $3.2 \pm 0.17$ \\
\hline 4000 & $0.26 \pm 0.007$ & $148.3 \pm 6.21$ & $46.2 \pm 4.31$ & $1.28 \pm 0.35$ & $93.2 \pm 20.79^{*}$ & $5.3 \pm 0.21^{*}$ & $3.7 \pm 0.21^{*}$ \\
\hline 8000 & $0.29 \pm 0.011^{*}$ & $141.0 \pm 4.27$ & $44.5 \pm 3.09$ & $1.13 \pm 0.14$ & $84.4 \pm 9.18^{*}$ & $5.3 \pm 0.21^{*}$ & $3.7 \pm 0.21^{*}$ \\
\hline
\end{tabular}

In two separate infections, each consisting of 30 fish $(n=6)$, fish were exposed to different concentrations of glochidia for $25 \mathrm{~min}$. After $24 \mathrm{~h}$, plasma from each fish was recovered and analyzed. Values are the mean $\pm \mathrm{SE}$ from data pooled from both sets of exposures $(n=12)(P<0.05)$. The time until juvenile shedding is the number of days post-infection before juveniles were first recovered from infected fish. The duration of juvenile shedding is the length of time during which juveniles were recovered from infected fish from the time of first juvenile shedding to the final emergence of juveniles from hosts. All values indicate the mean number of days $\pm \mathrm{SE}(P<0.05)$. Values with asterisks represent statistical differences between the treatment groups $(P<0.05)$. 

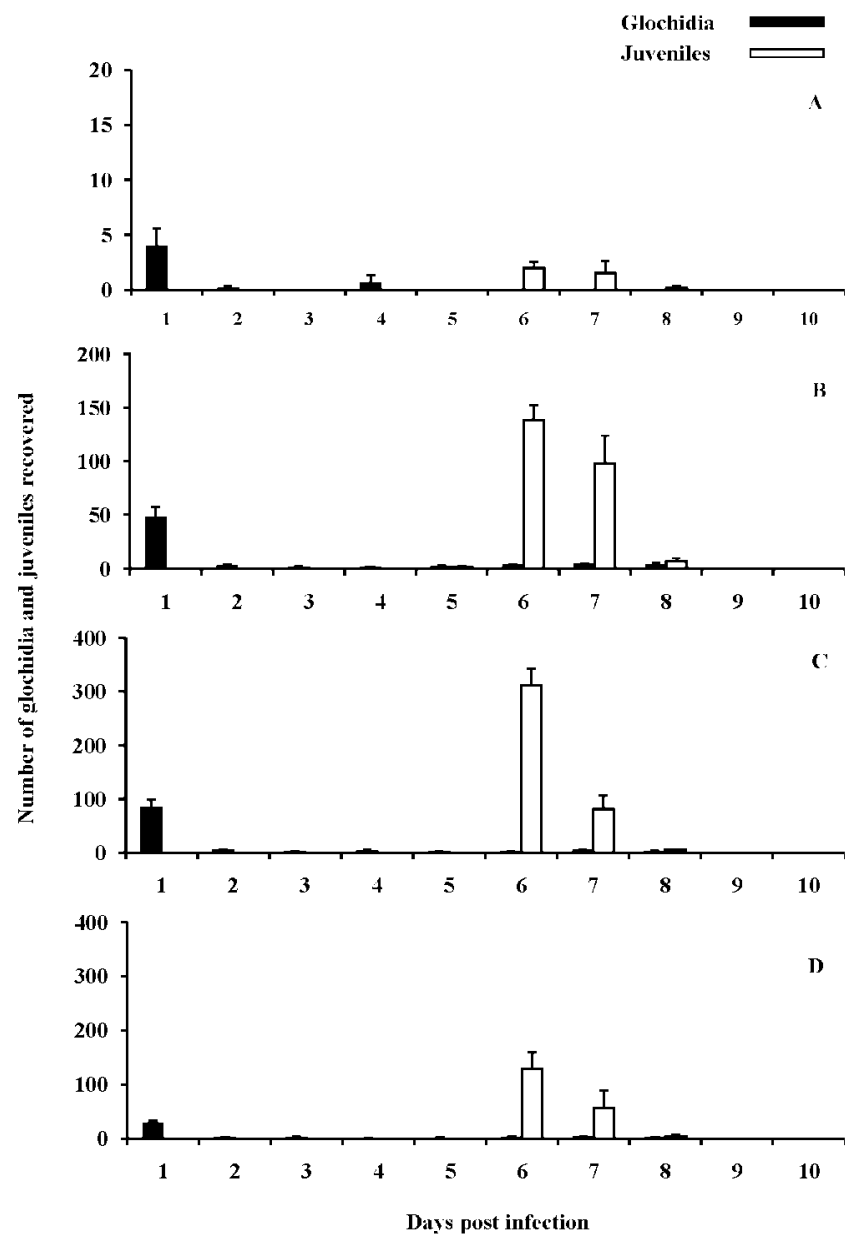

Figure 3. Number of glochidia and juvenile mussels recovered from host fish after exposure to (A) 1000, (B) 2000, (C) 4000, and (D) 8000 glochidia liter ${ }^{-1}$ for $25 \mathrm{~min}$. Bars represent the mean number of glochidia or juveniles recovered each day $\pm \mathrm{SE}(n=6$ per treatment $)$ post-infection for 10 days.

\section{Discussion}

All species of North American unionid mussels must undergo an obligatory parasitism of specific hosts in order to metamorphose from glochidia into free-living juveniles (Bogan and Roe, 2008). After a glochidium attaches to a fish, epithelial cells and connective tissue migrate to encapsulate the larval mussel, forming a cyst that protects it from the aquatic environment. Cyst formation, which is likely an intrinsic reaction of the gill epithelium to invasion by a foreign object, is remarkably fast in fish (Quilhac and Sire, 1998, 1999). In most cases, glochidia utilize the gill epithelium of fish as their primary site of infection, although other external structures such as fins may also serve as important substrates for attachment for some species (Barnhart et al., 2008). Since the gills receive the entire cardiac output of the fish and play such a pivotal role in maintaining overall health, any gill injury or pathogen that enters through the
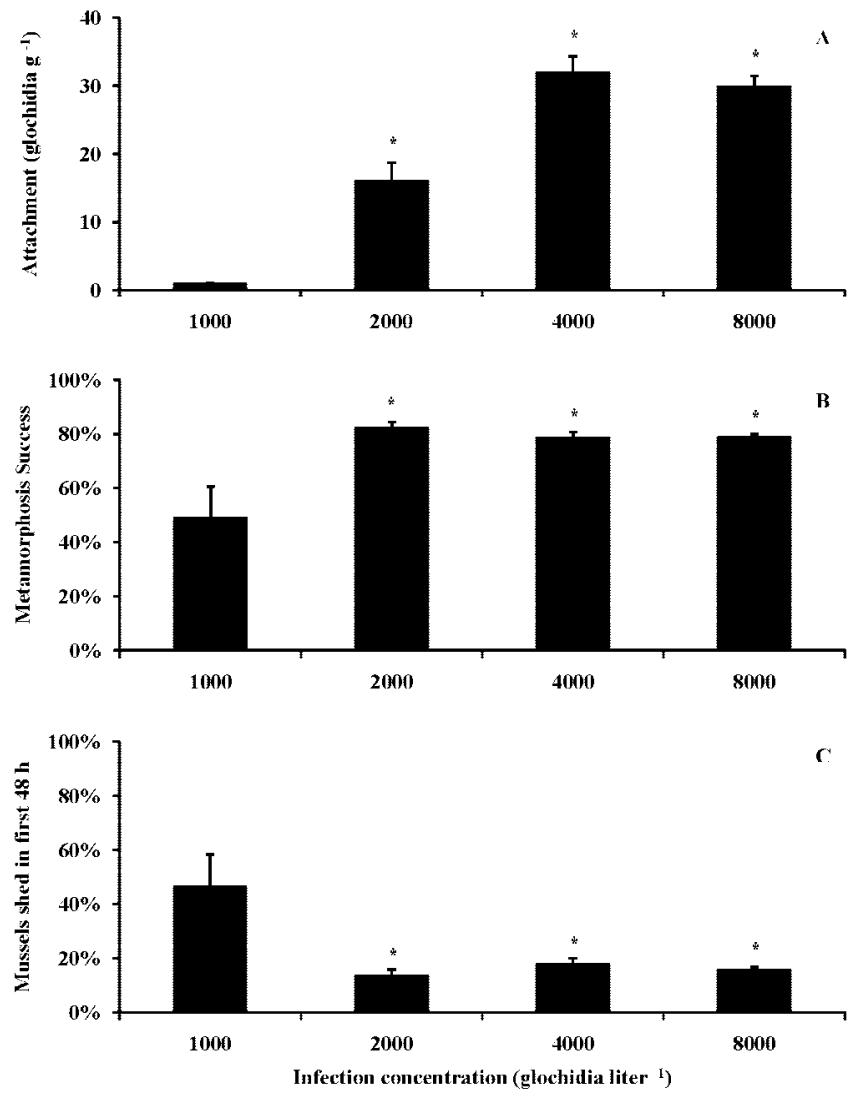

Figure 4. Glochidia attachment, metamorphic success, and the percentage of glochidia shed during the first $48 \mathrm{~h}$ post-infection for fish

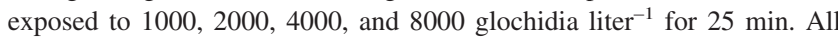
values are expressed as means $\pm \mathrm{SE}(n=6$ per treatment). Bars with

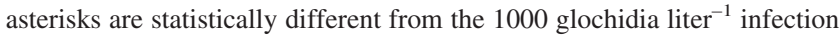
concentration. (A) Values represent the number of attached glochidia $\mathrm{g}^{-1}$ fish $(P<0.001)$. (B) Values represent the metamorphic success expressed as a percentage of the total number of attached glochidia $(P<0.01)$. (C) Values represent the average percentage of glochidia shed in the first $48 \mathrm{~h}$ as a percentage of the total number of attached glochidia collected $(P<$ $0.001)$.

gill can have far-reaching effects on the physiology of the animal.

In the present study, we evaluated the effects of glochidial exposure at 24 -h post-infection on various physiological endpoints in bluegill. We found that glochidia had few effects on the physiology of bluegill after acute exposure to concentrations of up to 8000 glochidia liter $^{-1}$. However, plasma cortisol was found to be a sensitive indicator of effect in fish hosts, becoming significantly elevated at infection concentrations at or above 2000 glochidia liter $^{-1}$. Cortisol, the primary corticosteroid in fish (Tully and Nolan, 2002), can be induced within minutes by a variety of physiological and environmental stressors (Bonga, 1997). Unlike other stress-induced factors such as catecholamine release, which are only transiently affected, cortisol stimulation can persist over time, making it a suitable marker of stress in 


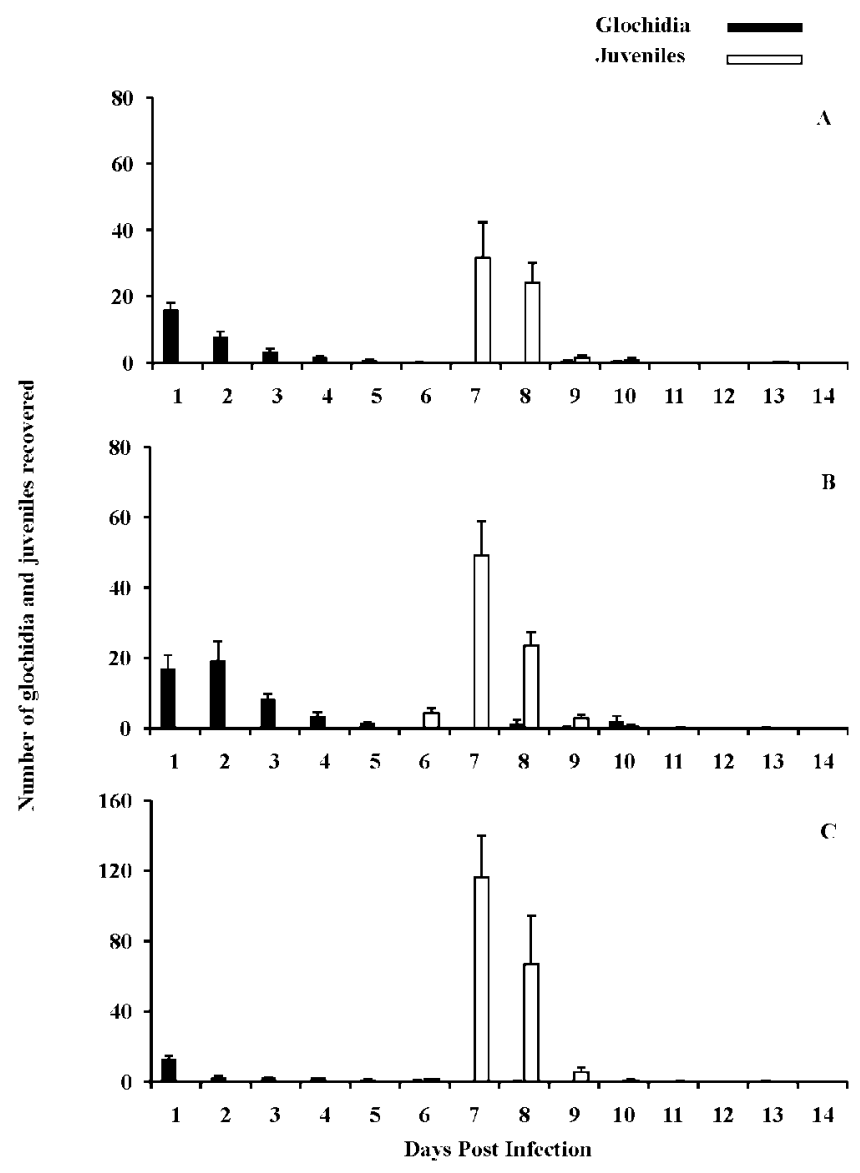

Figure 5. Number of glochidia and juvenile mussels recovered from host fish after exposure to 1000 glochidia liter $^{-1}$ for $25 \mathrm{~min}$ for (A) fish serving as non-injection controls, (B) fish given an intraperitoneal injection of coconut oil (sham-injected) $48 \mathrm{~h}$ prior to infection, and (C) fish given an intraperitoneal injection of cortisol dissolved in coconut oil $48 \mathrm{~h}$ prior to infection. Bars represent the mean number of glochidia or juveniles recovered each day $\pm \operatorname{SE}(n=6$ per treatment) post-infection for 14 days.

fish (Bonga, 1997; Portz et al., 2006). Although cortisol is capable of affecting carbohydrate metabolism (Bonga, 1997; Vijayan et al., 1997; Mommsen et al., 1999), we found no effect of glochidial exposure on either plasma glucose or plasma lactate. However, it remains unclear whether cortisol levels were simply insufficient to stimulate these secondary responses in hosts, or whether these factors recovered over the 24-h post-infection period (Pickering and Pottinger, 1989). Following infection, glochidia typically take hours to become completely encapsulated. Despite this, damage ensuing from glochidial attachment would be expected to reduce plasma $\mathrm{Na}^{+}$in hosts due to ion loss to the dilute fresh water. In contrast, we found no effect of glochidial infection on this critical plasma osmolyte, suggesting either that the level of gill damage was relatively minor or that any ionoregulatory impairment during cyst formation was quickly remedied. Certainly, epithelial remodeling in fish is fast compared to that observed in most
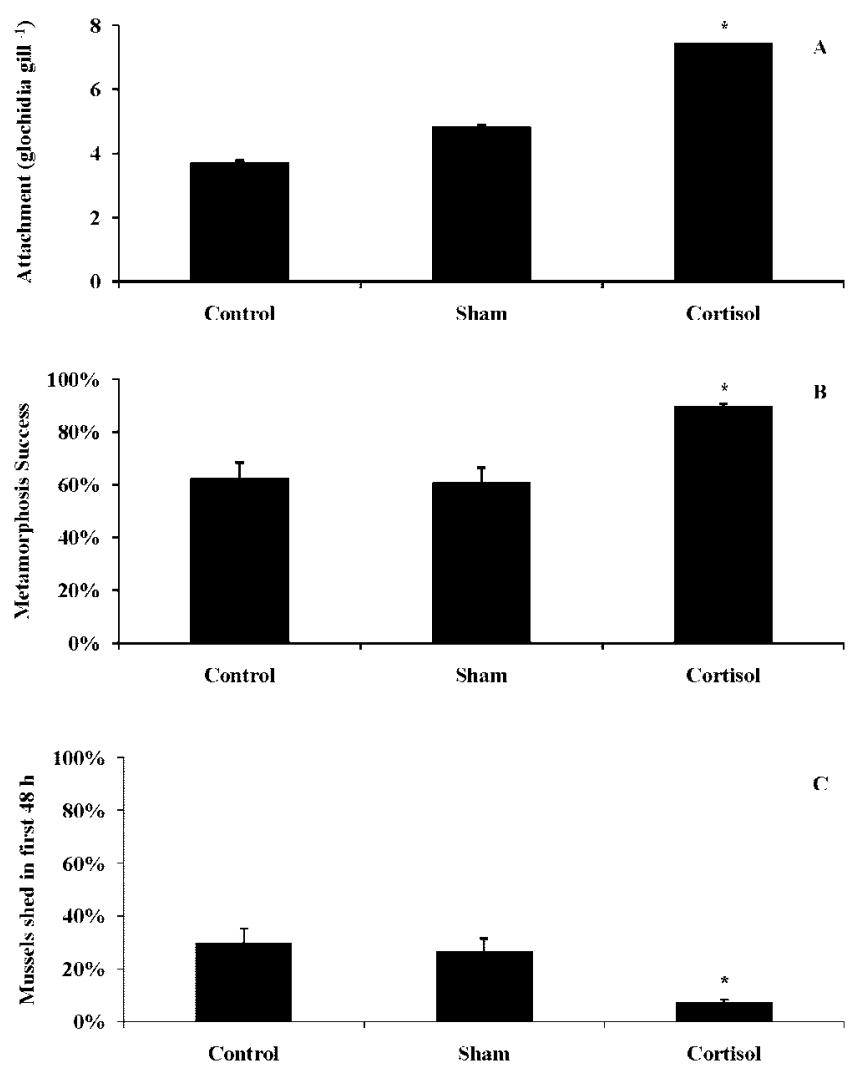

Figure 6. Glochidia attachment, metamorphic success, and percentage of immature glochidia shed from non-injection control fish, or from fish either injected with coconut oil (sham-injected), or injected with cortisol

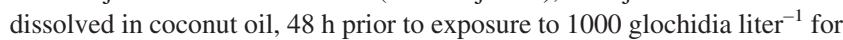
25 min. All values are expressed as means $\pm \operatorname{SE}(n=6$ per treatment). Bars with asterisks represent statistical difference between the cortisolinjected treatment group and the control (non-injected) and/or sham (coconut oil-injected) treatment groups determined using the Kruskall-Wallis test, followed by Dunn's pairwise comparison (panels A and B) or Tukey's multiple range test (panel C). (A) Values represent the number of attached glochidia $\mathrm{g}^{-1}$ fish $(P=0.01)$ for cortisol-injected fish compared to control fish. (B) Values represent the metamorphic success expressed as a percentage of the total number of attached glochidia $(P \leq 0.004)$ for cortisolinjected fish compared to control and sham-injected fish. (C) Values represent the mean percentage of glochidia shed in the first $48 \mathrm{~h}$ as a percentage of the total number of attached glochidia $(P \leq 0.02)$ for cortisol-injected fish compared to control and sham-injected fish.

other animals, presumably due to the inherent risks of failure to maintain ion balance in an aquatic environment (Quilhac and Sire, 1998, 1999).

Two of the more notable results of this study were that hosts with elevated plasma cortisol also had a greater number of glochidia attach gram ${ }^{-1}$ fish and that a greater proportion of those attached glochidia successfully underwent metamorphosis. The timing of glochidial and juvenile shedding indicated that this effect on metamorphosis was due to events taking place in the first 2 days after infection (see below). This was followed by an interim period during which few larvae or juveniles excysted from their hosts. The 
bulk of the juveniles emerged during a final pulse lasting 2-3 days. In addition, there was also a slight treatment effect on the time required to metamorphose (Table 1). Fish infected with 1000 glochidia liter $^{-1}$ lost $47 \%$ of all attached mussels within 2 days after infection. Worth reiterating is that fish infected at a concentration of 1000 glochidia liter $^{-1}$ did not experience an increase in plasma cortisol relative to non-exposure controls (Fig. 2). This is in stark contrast to the $14 \%-18 \%$ of attached mussels that were lost from the hosts within $48 \mathrm{~h}$ after infection with larval exposures at or greater than 2000 glochidia liter $^{-1}$ (Fig. 4C). In other words, cortisol appeared to enhance glochidial survivorship past 2 days post-infection. Furthermore, for glochidia passing through this critical stage, the majority went on to successfully metamorphose into juveniles. In fact, there was little change in metamorphic success rates between treatment groups (89\%-96\% for all treatment groups) when the number of mussels shed in the first $48 \mathrm{~h}$ was removed from the total number of mussels during calculations of metamorphic success. These data suggest that cortisol-related mechanisms active during the first $48 \mathrm{~h}$ are largely responsible for the successful metamorphosis of glochidia to the juvenile stage. It also suggests that high infection intensity can induce an increase in plasma cortisol that can stimulate glochidial metamorphosis. The results of this study are in accordance with others that have demonstrated that a large proportion of attached glochidia fail to metamorphose into juveniles, tending to slough prematurely from fish shortly after infection (Waller and Mitchell, 1989; Rogers and Dimock, 2003). It appears that these early shedding events are largely responsible for the inability of glochidia to persist on non-host fish species or on fish that have developed resistance to glochidia after repeated infections (Waller and Mitchell, 1989; Rogers and Dimock, 2003).

To investigate more closely this potential link between plasma cortisol and glochidial attachment and/or metamorphosis, we monitored glochidial attachment after altering host physiology. After administering a physiologically relevant dose of cortisol, we exposed fish to glochidia at a concentration that we had previously found not to elicit a stress response (i.e., 1000 glochidia liter $^{-1}$ ). Using this method, we were able to verify that hosts with elevated cortisol had significantly more glochidia attached gram $^{-1}$ fish, and that these attached glochidia had a greater probability of successfully undergoing metamorphosis (Fig. 6A, B). It is not surprising that an increase in cortisol could be associated with an increase in attachment of glochidia. Cortisol is known to increase the susceptibility of fish to bacterial and fungal infections and makes hosts less resistant to ectoparasitic infection (Harris and Bird, 2000; Davis et al., 2002, 2003). It has also been reported to induce the metamorphosis of glochidia on non-host fish (Kirk and Layzer, 1997). It follows that stimulatory effects of cortisol could be operating through similar mechanisms on host fish.
In general, cortisol administration reduces hyperplasia and inflammation, which are both pathologies associated with activation of the innate immune system. Stimulation of host immunity stemming from a change in leukocyte distribution near cysts has been proposed as a mechanism for rejection of attached glochidia (Waller and Mitchell, 1989). Eosinophilic granular cells in and around the glochidial cyst are reported as being fewer in the gills of more suitable host fish (Waller and Mitchell, 1989). The presence of this cell type around areas of infection is pervasive in vertebrates, and it has been described numerous times in fish infected with ectoparasites. Additionally, inflammatory responses are generally less pronounced in fish that are suitable hosts. This parallels the presence of an inflammatory response in coho salmon (Oncorhynchus kisutch) resistant to the ectoparasite Lepeophtheirus salmonis, or to the lack of this response in Atlantic salmon (Salmo salar), which are susceptible to these parasites (Fast et al., 2006). However, the immunosuppressant properties of cortisol are only a part of a wide range of actions elicited by this hormone. In addition to a decrease in immunity, the acute effects of this release of circulating hormones are manifold and include an increase in metabolism, which can lead to increased ventilation at the gill (Bonga, 1997). This increase in ventilation could lead to increased accumulation of glochidia in the gill by bringing higher numbers of the larvae into direct contact with the respiratory surface. In fact, glochidial attachment has been classically used as a method of assessing ventilation rates in fish (Paling, 1968). It appears that an understanding of the relationship between fish mass, gill surface area, and gill ventilation is integral to understanding the potential of a gill to act as a suitable surface for glochidial attachment. As we have found when performing initial infections to determine the optimal fish size for these experiments, attachment of Utterbackia imbecillis to the gills of bluegill sunfish positively correlates with fish mass. However, we have insufficient data to describe this relationship in detail.

The physiological status of the host, including variations in hormone levels (i.e., plasma cortisol; McCormick, 2001), acid-base status (Cameron and Iwama, 1987; Goss et al., 1992, 1994, 1998), and ion balance, may influence the capacity of the fish gill to undergo epithelial remodeling during cyst formation. These factors may influence the fish gill directly, or they may elicit classical stress responses, which may indirectly influence fish gill remodeling. Furthermore, handling and confinement associated with initial infections were suspected of inducing considerable stress in experimental animals (Reddy et al., 1995; Bonga, 1997; Vijayan et al., 1997; Davis et al., 2002). Efforts to reduce human interaction were made where possible. The steps leading up to infection were planned to minimize direct contact with the fish. Although transfer from the infection chambers to the individual tanks for monitoring metamor- 
phosis was favored over monitoring the fish as a group, this produced only a negligible increase in plasma cortisol.

Most of the research on the early life stages of unionid mussels has focused on understanding the ecology of these animals (Strayer, 2008). Due to the threatened status of unionid mussels, conservation strategies have included the establishment of artificial propagation programs. Identifying natural fish hosts that can be used in such programs is critical to the management and protection of unionid mussels. Monitoring metamorphosis on individual fish can characterize the degree of compatibility between fish hosts and mussel species. Using modifications of standard techniques for laboratory infection and subsequent monitoring of metamorphosis of glochidia on individual fish (Dodd et al., 2005; Rogers-Lowery and Dimock, 2006), we have described a possible role of fish stress on the efficacy of glochidial attachment and metamorphosis.

It is currently unknown what consequences a reduction in fish stress during infection will have on the acquisition of immunity from multiple exposures to glochidia, although it is likely that low-level infections will prime the immunological memory, and that both administered and stressrelated endogenous cortisol could lessen this adaptive response, resulting in an increase in successful metamorphosis. The stress associated with high levels of infection could also influence the degree of resistance that accumulates after a fish is infected multiple times. It is likely that stress-free infection systems could be applied to multiple infection studies to reduce handling and crowding stress associated with traditional laboratory infection methods. A better understanding of the physiological effects of glochidial attachment and how host physiology influences glochidial attachment and metamorphosis is likely to provide useful information for conservation efforts.

\section{Acknowledgments}

We thank Drs. Malcolm Vidrine and Thomas Deitz for assistance in the identification of mussel sampling sites around the Baton Rouge area. This work was funded by grants from the Louisiana Board of Regents IRC subprogram to FG and the Louisiana Department of Wildlife and Fisheries to BD and FG.

\section{Literature Cited}

Arey, L. B. 1921. An experimental study on glochidia and the factors underlying encystment. J. Exp. Zool. 33: 463-499.

Arey, L. B. 1932. The formation and structure of the glochidial cyst. Biol. Bull. 62: 212-221.

Barnhart, M. C., W. R. Haag, and W. N. Roston. 2008. Adaptations to host infection and larval parasitism in Unionoida. J. North Am. Benthol. Soc. 27: 370-394.

Bauer, G., and C. Vogel. 1987a. The parasitic stage of the freshwater pearl mussel (Margaritifera margaritifera L.). I. Host response to glochidiosis. Arch. Hydrobiol. 76: 393-402.
Bauer, G., and C. Vogel. 1987b. The parasitic stage of the freshwater pearl mussel (Margaritifera margaritifera L.). III. Host relationships. Arch. Hydrobiol. 76: 413-423.

Bogan, A. E. 1993. Fresh-water bivalve extinctions (Mollusca, Unionida)—a search for causes. Am. Zool. 33: 599-609.

Bogan, A. E., and K. Roe. 2008. Freshwater bivalve (Unioniformes) diversity, systematics, and evolution: status and future directions. $J$. North Am. Benthol. Soc. 27: 349-369.

Bonga, S. E. W. 1997. The stress response in fish. Physiol. Rev. 77: 591-625.

Cameron, J. N., and G. K. Iwama. 1987. Compensation of progressive hypercapnia in channel catfish and bluecrabs. J. Exp. Biol. 133: 183197.

Campos-Perez, J. J., M. Ward, P. S. Grabowski, A. E. Ellis, and C. J. Secombes. 2000. The gills are an important site of iNOS expression in rainbow trout Oncorhynchus mykiss after challenge with the grampositive pathogen Renibacterium salmoninarum. Immunology 99: 153161.

Davis, K. B., B. R. Griffin, and W. L. Gray. 2002. Effect of handling stress on susceptibility of channel catfish (Ictalurus punctatus) to Icthyophthirius multifiliis and channel catfish virus infection. Aquaculture 214: 55-66.

Davis, K. B., B. R. Griffin, and W. L. Gray. 2003. Effect of dietary cortisol on resistance of channel catfish to infection by Ichthyopthirius multifiliis and channel catfish virus disease. Aquaculture 218: 121-130.

Dietz, T. H., D. Lessard, H. Silverman, and J. W. Lynn. $1994 . \quad$ Osmoregulation in Dreissena polymorpha: the importance of $\mathrm{Na}, \mathrm{Cl}, \mathrm{K}$, and particularly Mg. Biol. Bull. 187: 76-83.

Dodd, B. J., M. C. Barnhart, C. L. Rogers-Lowery, T. B. Fobian, and R. V. Dimock. 2005. Cross-resistance of largemouth bass to glochidia of unionid mussels. J. Parasitol. 91: 1064-1072.

Dodd, B. J., M. C. Barnhart, C. L. Rogers-Lowery, T. B. Fobian, and R. V. Dimock. 2006. Persistence of host response against glochidia larvae in Micropterus salmoides. Fish Shellfish Immunol. 21: 473-484.

Evans, D. H., P. M. Piermarini, and K. P. Choe. 2005. The multifunctional fish gill: dominant site of gas exchange, osmoregulation, acid-base regulation, and excretion of nitrogenous waste. Physiol. Rev. 85: $97-177$.

Fast, M. D., D. M. Muise, R. E. Easy, N. W. Ross, and S. C. Johnson. 2006. The effects of Lepeophtheirus salmonis infections on the stress response and immunological status of Atlantic salmon (Salmo salar). Fish Shellfish Immunol. 21: 228-241.

Fustish, C. A., and R. E. Millemann. 1978. Glochidiosis of salmonid fishes. II. Comparison of tissue response of coho and chinook salmon to experimental infection with Margaritifera margaritifera (L.) (Pelecypoda: Margaritanidae). J. Parasitol. 64: 155-157.

Gillis, P. L., R. J. Mitchell, A. N. Schwalb, K. A. McNichols, G. L. Mackie, C. M. Wood, and J. D. Ackerman. 2008. Sensitivity of the glochidia (larvae) of freshwater mussels to copper: assessing the effect of water hardness and dissolved organic carbon on the sensitivity of endangered species. Aquat. Toxicol. 88: 137-145.

Goss, G., P. Laurent, and F. Perry. 1992. Evidence for a morphological component in acid-base regulation during environmental hypercapnia in the brown bullhead (Ictalurus nebulosus). Cell Tissue Res. 268: $539-552$.

Goss, G. G., P. Laurent, and S. F. Perry. 1994. Gill morphology during hypercapnia in brown bullhead (Ictalurus nebulosus)—role of chloride cells and pavement cells in acid-base regulation. J. Fish Biol. 45: 705-718.

Goss, G. G., S. F. Perry, J. N. Fryer, and P. Laurent. 1998. Gill morphology and acid-base regulation in freshwater fishes. Comp. Biochem. Physiol. Part A Mol. Integr. Physiol. 119: 107-115.

Grabarkiewicz, J., and W. Davis. 2008. An Introduction to Freshwater Mussels as Biological Indicators. U.S. Environmental Protection 
Agency, Office of Environmental Information, Washington, DC. EPA260-R-08-015.

Harris, J., and D. J. Bird. 2000. Modulation of the fish immune system by hormones. Vet. Immunol. Immunopathol. 77: 163-176.

Howerth, E. W., and A. E. Keller. 2006. Experimentally induced glochidiosis in smallmouth bass (Micropterus dolomieu). Vet. Pathol. 43: $1004-1008$.

Jones, J. W., R. A. Mair, and R. J. Neves. 2005. Factors affecting survival and growth of juvenile freshwater mussels cultured in recirculating aquaculture systems. N. Am. J. Aquac. 67: 210-220.

Karna, D. W., and R. E. Millemann. 1978. Glochidiosis of salmonid fishes. III. Comparative susceptibility to natural infection with Margaritifera margaritifera (L.) (Pelecypoda: Margaritanidae) and associated histopathology J. Parasitol. 64: 528-537.

Kirk, S. G., and J. B. Layzer. 1997. Induced metamorphosis of freshwater mussel glochidia on nonhost fish. Nautilus 110: 102-106.

McCormick, S. D. 2001. Endocrine control of osmoregulation in teleost fish. Am. Zool. 41: 781-794.

Meyers, T. R., and R. E. Millemann. 1977. Glochidiosis of salmonid fishes. I. Comparative susceptibility to experimental infection with Margaritifera margaritifera (L.) (Pelecypoda: Margaritanidae). J. Parasitol. 63: 728-733.

Meyers, T. R., R. E. Millemann, and C. A. Fustish. 1980. Glochidiosis of salmonid fishes. IV. Humoral and tissue responses of coho and chinook salmon to experimental infection with Margaritifera margaritifera (L.) (Pelecypoda: Margaritanidae). J. Parasitol. 66: 274-281.

Mommsen, T. P., M. M. Vijayan, and T. W. Moon. 1999. Cortisol in teleosts: dynamics, mechanisms of action, and metabolic regulation. Rev. Fish. Biol. Fish. 9: 211-268.

Paling, J. E. 1968. A method of estimating the relative volumes of water flowing over the different gills of a freshwater fish. J. Exp. Biol. 48: 533-544.

Perry, S. F., and K. M. Gilmour. 2006. Acid-base balance and $\mathrm{CO}_{2}$ excretion in fish: unanswered questions and emerging models. Respir. Physiol. Neurobiol. 154: 199-215.

Pickering, A. D., and T. G. Pottinger. 1989. Stress response and disease resistance in salmonid fish-effects of chronic elevation on plasma cortisol. Fish Physiol. Biochem. 7: 253-258.

Portz, D. E., C. M. Woodley, and J. J. Cech. 2006. Stress-associated impacts of short-term holding on fishes. Rev. Fish Biol. Fish. 16: 125-170.

Quilhac, A., and J. Y. Sire. 1998. Restoration of the subepidermal tissues and scale regeneration after wounding a cichlid fish, Hemicromis bimaculatus. J. Exp. Zool. 281: 305-327.
Quilhac, A., and J. Y. Sire. 1999. Spreading, proliferation, and differentiation of the epidermis after wounding a cichlid fish, Hemichromis bimaculatus. Anat. Rec. 254: 435-451.

Reddy, P. K., M. M. Vijayan, J. F. Leatherland, and T. W. Moon. 1995. Does RU486 modify hormonal responses to handling stressor and cortisol treatment in fed and fasted rainbow trout? J. Fish Biol. 46: 341-359.

Reuling, F. H. 1919. Acquired immunity to an animal parasite. J. Infect. Dis. 24: 337-346.

Rogers, C. L., and R. V. Dimock. 2003. Acquired resistance of bluegill sunfish (Lepomis macrochirus) to glochidia larvae of the freshwater mussel Utterbackia imbecillis (Bivalvia: Unionidae) after multiple infections. J. Parasitol. 89: 51-56.

Rogers-Lowery, C. L., and R. V. Dimock. 2006. Encapsulation of attached ectoparasitic glochidia larvae of freshwater mussels by epithelial tissue on fins of naive and resistant host fish. Biol. Bull. 210: $51-63$.

Sollid, J., and G. E. Nilsson. 2006. Plasticity of respiratory structuresadaptive remodeling of fish gills induced by ambient oxygen and temperature. Respir. Physiol. Neurobiol. 154: 241-251.

Strayer, D. L. 2008. Freshwater Mussel Ecology: A Multifactor Approach to Distribution and Abundance. University of California Press, Berkeley.

Tully, O., and D. T. Nolan. 2002. A review of the population biology and host-parasite interactions of the sea louse Lepeophtheirus salmonis (Copepoda: Caligidae). Parasitology 124: S165-S182.

Vijayan, M. M., C. Pereira, E. G. Grau, and G. K. Iwama. 1997. Metabolic responses associated with confinement stress in tilapia: the role of cortisol. Comp. Biochem. Physiol. C Pharmacol. Toxicol. Endocrinol. 116: 89-95.

Waller, D. L., and L. G. Mitchell. 1989. Gill tissue reactions in walleye Stizostedion vitreum vitreum and common carp Cyprinus carpio to glochidia of the freshwater mussel Lampsilis radiata siliquoidea. Dis. Aquat. Org. 6: $81-87$.

Watters, G. T., and S. H. O'Dee. 1998. Metamorphosis of freshwater mussel glochidia (Bivalvia: Unionidae) on amphibians and exotic fishes. Am. Midl. Nat. 139: 49-57.

Watters, G. T., and S. H. O'Dee. 1999. Glochidia of the freshwater mussel Lampsilis overwintering on fish hosts. J. Molluscan Stud. 65: 453-459.

Williams, J. D., M. L. Warren, K. S. Cummings, J. L. Harris, and R. J. Neves. 1993. Conservation status of freshwater mussels of the United States and Canada. Fisheries 18: 6-22. 